\title{
Research on Evaluation of Human Resources Competitiveness of Small and Medium Enterprises Based on FCE
}

\author{
Xinyi Wu \\ Wu Han University of Technology, Wu Han, China
}

Keywords: SMEs; Enterprise human resources competitiveness; Fuzzy comprehensive evaluation

\begin{abstract}
The importance of human resources to promote the sustainable development of enterprises is self-evident. For Small and Medium Enterprises(SMEs), human resources are an important support for the formation of competitive advantages. However, the current SMEs generally ignore the importance of human resources in the development process, resulting in insufficient human resources competitiveness. Based on the existing research results of human resources competitiveness evaluation, this paper starts from the four dimensions of human resource performance, practice, quality and environment, and establishes a human resource competitiveness evaluation system that is consistent with the characteristics of SMEs, and adopts fuzzy comprehensive evaluation. Case Study of Company A as an Example
\end{abstract}

\section{Introduction}

SMEs are economic units with smaller assets and scales in the industry compared to large enterprises. In the era of knowledge economy, intellectual capital with high-quality human resources as the carrier has become the main body of enterprise competition. ${ }^{[1]}$ However, Chinese SMEs, as the main players in the market, generally ignore the importance of human resources, resulting in insufficient human resources competitiveness and lack of sustainability in corporate development. This paper takes SMEs as the research object, builds the human resource competitiveness evaluation system which is consistent with the characteristics of SMEs based on the integration of existing research results, and adopts the FCE method to evaluate the current situation of human resources of enterprises, helping SMEs to correctly understand them. The advantages and disadvantages of human resources in the development process.

\section{View}

Since IMD and WEF proposed the national human resources competitiveness evaluation system at the end of the last century, research in this area has gradually increased. Ramsuoair pointed out that human resources competitiveness should be analyzed from both stock and quality. ${ }^{[2]}$ Maura Sheehan used 336 SMEs in the UK as samples to find effective human resource management. It is directly proportional to the performance of SMEs. ${ }^{[3]}$

Domestic research started late but developed rapidly. Xiuhua Liu started from the factors necessary for the formation of human resources competitiveness, and established 13 secondary factors including the quantity and quality of human resources, management system, capability status, market performance, and the incentive mechanism and market share. ${ }^{[4]}$ Within the evaluation system; Ming Li started to establish an evaluation system from four aspects: employee skill, employment mechanism, market ability and development ability; ${ }^{[5]}$ Dandan Xie selected three dimensions of human resources work, atmosphere and quality for the service characteristics of airlines, including Evaluation system of 19 sub-indicators such as employee satisfaction. ${ }^{[6]}$

Based on the above analysis, this paper finds that there are still many research gaps in the existing research, mainly in the following two aspects: First, there are few studies on SMEs; Second, the internal and external conditions affecting enterprises are not comprehensively considered, and the evaluation indicators are not comprehensively set. 


\section{Construction of evaluation system}

Evaluation system design. Combining with the statusquo of the development of human resources in SMEs, drawing on the research results of the evaluation system of human resources competitiveness of existing enterprises, this paper proposes including human resource performance, human resource practice, and human resources. The resource quality and human resources environment four dimensions, 12 elements, a total of 34 indicators of SMEs human resources competitiveness evaluation index system, as shown in Table 1.

Table 1 SMEs Human Resource Competitiveness(A) Evaluation System

\begin{tabular}{|c|c|c|}
\hline Dimension & Element & Index \\
\hline \multirow{7}{*}{$\begin{array}{l}\qquad \mathrm{B}_{1} \\
\text { Human resource } \\
\text { performance }\end{array}$} & \multirow{3}{*}{$\begin{array}{c}\mathrm{C}_{1} \\
\text { Human resources } \\
\text { financial performance }\end{array}$} & $\mathrm{D}_{1}$ Market share \\
\hline & & $\mathrm{D}_{2}$ Per capita profit margin \\
\hline & & $\mathrm{D}_{3}$ Human resource cost ratio \\
\hline & \multirow{4}{*}{$\begin{array}{c}\mathrm{C}_{2} \\
\text { Human resources } \\
\text { non-financial } \\
\text { performance }\end{array}$} & $\mathrm{D}_{4}$ Innovation and Patent Number \\
\hline & & $\mathrm{D}_{5}$ Corporate Culture Recognition \\
\hline & & $\mathrm{D}_{6}$ Corporate Social Responsibility \\
\hline & & $\mathrm{D}_{7}$ employee turnover rate \\
\hline \multirow{15}{*}{$\begin{array}{c}\mathrm{B}_{2} \\
\text { Human resource } \\
\text { practice }\end{array}$} & \multirow{2}{*}{$\begin{array}{c}\mathrm{C}_{3} \\
\text { Human resources } \\
\text { strategic planning }\end{array}$} & $\mathrm{D}_{8}$ HR Management Strategy Participation \\
\hline & & $\mathrm{D}_{9}$ Organizational structure rationality \\
\hline & \multirow{3}{*}{$\begin{array}{c}\mathrm{C}_{4} \\
\text { Recruitment and } \\
\text { configuration }\end{array}$} & $\mathrm{D}_{10}$ Recruitment Process Normative \\
\hline & & $\mathrm{D}_{11}$ Recruitment completion ratio \\
\hline & & $\mathrm{D}_{12}$ Recruitment cost-to-cost ratio \\
\hline & \multirow{3}{*}{$\begin{array}{c}\mathrm{C}_{5} \\
\text { Training and } \\
\text { development }\end{array}$} & $\mathrm{D}_{13}$ Training Process Normative \\
\hline & & $\mathrm{D}_{14}$ per capita training times \\
\hline & & $\mathrm{D}_{15}$ Training ROI \\
\hline & \multirow{2}{*}{$\begin{array}{c}\mathrm{C}_{6} \\
\text { Performance } \\
\text { management } \\
\end{array}$} & $\begin{array}{l}\mathrm{D}_{16} \text { Rationality of performance appraisal } \\
\text { indicators }\end{array}$ \\
\hline & & $\mathrm{D}_{17}$ Performance feedback effectiveness \\
\hline & \multirow{3}{*}{$\begin{array}{l}\mathrm{C}_{7} \\
\text { Salary and benefits }\end{array}$} & $\mathrm{D}_{18}$ Salary level competitiveness \\
\hline & & $\mathrm{D}_{19}$ Employee Benefit Satisfaction \\
\hline & & $\mathrm{D}_{20}$ Incentive System Effectiveness \\
\hline & \multirow{2}{*}{$\begin{array}{c}\mathrm{C}_{8} \\
\text { Promotion and } \\
\text { development }\end{array}$} & $\mathrm{D}_{21}$ Promotion mechanism rationality \\
\hline & & $\mathrm{D}_{22}$ Team learning atmosphere \\
\hline \multirow{8}{*}{$\begin{array}{c}\mathrm{B}_{3} \\
\text { Human resource } \\
\text { quality }\end{array}$} & \multirow{4}{*}{$\begin{array}{l}\mathrm{C}_{9} \\
\text { Human resource structure }\end{array}$} & $\mathrm{D}_{23}$ Undergraduate employees \\
\hline & & $\mathrm{D}_{24}$ Master's and above employees \\
\hline & & $\mathrm{D}_{25}$ Intermediate Title Employees \\
\hline & & $\mathrm{D}_{26}$ Proportion of senior titles \\
\hline & \multirow{4}{*}{$\begin{array}{l}\mathrm{C}_{10} \\
\text { Human resource quality }\end{array}$} & $\mathrm{D}_{27}$ Decision-making ability of leaders \\
\hline & & $\mathrm{D}_{28}$ Management team building level \\
\hline & & $\mathrm{D}_{29}$ Employee position competency \\
\hline & & $\mathrm{D}_{30}$ Employee learning ability \\
\hline \multirow{4}{*}{$\begin{array}{c}\mathrm{B}_{4} \\
\text { Human resources } \\
\text { environment }\end{array}$} & \multirow{2}{*}{$\begin{array}{c}\mathrm{C}_{11} \\
\text { Political and legal } \\
\text { environment }\end{array}$} & $\mathrm{D}_{31}$ Government policy support \\
\hline & & $\mathrm{D}_{32}$ Legal soundness and universal ability \\
\hline & \multirow{2}{*}{$\begin{array}{c}\mathrm{C}_{12} \\
\text { Economic and social } \\
\text { environment }\end{array}$} & $\mathrm{D}_{33}$ Regional development level \\
\hline & & $\mathrm{D}_{34}$ Labor Market Suppl \\
\hline
\end{tabular}

Description of the evaluation indicators. Human resource performance is a result-oriented dimension and the most direct manifestation of enterprise human resource competitiveness. It is mainly measured from two aspects: financial performance and non-financial performance; human resource practice is indispensable for the formation of enterprise human resource competitiveness; human resources Quality performance is the level of work efficiency and value creation of employees. The human resources environment mainly refers to the macro external environment that affects the development of human resource. 


\section{Case study}

To further introduce the application of the evaluation system, this paper selects Company A as a case to illustrate. Founded in 2010, Company A is a pharmaceutical equipment industry company with more than 160 employees and an operating income of approximately 30 million in 2017 .

Fuzzy comprehensive evaluation(FCE) method. In view of the ambiguity and uncertainty of the evaluation indicators, this paper selects the FCE method to evaluate the human resources competitiveness of enterprises. The basic steps of the FCE are as follows:

(1) Determining the evaluation index set:There are $\mathrm{m}$ indicators reflecting the object to be evaluated, and the set of evaluation indicators formed is recorded as $U=\left\{\mathrm{u}_{1}, \mathrm{u}_{2},-, \quad, \mathrm{u}_{\mathrm{m}}\right\}$.

(2) Determine the evaluation level set: In this paper, there are $n=5$ grades, which are represented by $\mathrm{v}_{1}, \mathrm{v}_{2}, \cdots, \mathrm{v}_{5}$, respectively $\mathrm{V}=\left\{\mathrm{v}_{1}\left(\right.\right.$ very good), $\mathrm{v}_{2}$ (better), $\mathrm{v}_{3}$ (general ), $\mathrm{v}_{4}$ (poor), $\mathrm{v}_{5}$ (very poor) $\}$. For each indicator $\mathrm{u}_{\mathrm{i}}(\mathrm{i}=1,2,-\cdots, \mathrm{m})$, in the evaluation index set, analyze its membership degree rij for the evaluation level set $\mathrm{v}_{j}(\mathrm{j}=1,2, \cdots, n)$, and get the first The evaluation results of $\mathrm{i}$ indicators: $r_{i j}=\left(r_{i 1}, r_{i 2},-, \quad, r_{i n}\right)$, and normalized.

(3) Establish an evaluation matrix: After the evaluation of each index is completed, a comprehensive fuzzy matrix $\mathrm{R}$ is formed:

$$
R=\left|\begin{array}{ccccc}
r_{11} & r_{12} & r_{13} & r_{14} & r_{15} \\
r_{21} & r_{22} & r_{23} & r_{24} & r_{25} \\
\cdot & \cdot & \cdot & \cdot & \cdot \\
r_{m 1} & r_{m 2} & r_{m 3} & r_{m 4} & r_{m 5}
\end{array}\right|
$$

(4) Determining the weight vector: If the weight of the indicator ui is pi, the weight vector corresponding to the evaluation index set $U$ can be expressed as: $P=\left(p_{1}, p_{2}, \cdot, p_{m}\right)$, and for the weight $\mathrm{p}_{\mathrm{i}}, \mathrm{p}_{\mathrm{i}} \geq 0$, and $\Sigma \mathrm{p}_{\mathrm{i}}=1$.

(5) Fuzzy synthesis using weighted average operator: the matrix R is synthesized by the weight vector $\mathrm{P}$, and the fuzzy comprehensive evaluation result vector $\mathrm{S}$ is obtained by fuzzy operation.

$$
\mathrm{S}=\mathrm{P} \circ \mathrm{R}=\left(\mathrm{p}_{1}, \mathrm{p}_{2} ;, \mathrm{p}_{\mathrm{m}}\right) \circ\left[\begin{array}{lllll}
r_{11} & r_{12} & r_{13} & r_{14} & r_{15} \\
r_{21} & r_{22} & r_{23} & r_{24} & r_{25} \\
& & & & \\
r_{m 1} & r_{m 2} & r_{m 3} & r_{m 4} & r_{m 5}
\end{array}\right]=\left(\mathrm{s}_{1}, \mathrm{~s}_{2,}, \mathrm{~s}_{3}, \mathrm{~s}_{4}, \mathrm{~s}_{5}\right) \text {, }
$$

And $\mathrm{s}_{\mathrm{j}}=\min \left(1, \sum_{i=1}^{n} p_{i} r_{i j}\right)$, 。 is the fuzzy operator symbol.

(6) Evaluation result output and analysis: The output evaluation result vector $S=\left(s_{1}, s_{2}, \cdots, S_{n}\right)$, and $s_{j}$ indicates the degree to which the evaluated index belongs to the evaluation level $v_{j}$. The evaluation level $v_{j}$ corresponding to the largest $s_{j}$ in $S$ represents the maximum membership level of the evaluated index, that is, the evaluation result.

Evaluation process and result output. Using the established evaluation index system of human resources competitiveness of SMEs, the process of specific evaluation of A enterprises by FCE method is as follows: Firstly, the evaluation results of each index on five evaluation levels are determined by questionnaire survey, and the evaluation matrix is formed. Secondly, the analytic hierarchy process is used to determine the weight of each evaluation index; then the fuzzy synthesis of the evaluation matrix and the index weight is carried out according to the weighted fuzzy operator calculation rule; finally, the fuzzy evaluation result is in Table2. 
Table 2 FCE result output

\begin{tabular}{|c|c|c|c|c|c|c|c|}
\hline$S_{c 2}=(0.26$ & 0.34 & $0.24 \quad 0.12$ & $0.04)$ & $S_{B 1}=\left(\begin{array}{ll}0.17 & 0.29\end{array}\right.$ & 0.28 & 0.18 & $0.08)$ \\
\hline$S_{c 3}=(0.15$ & 0.24 & $0.30 \quad 0.21$ & $0.10)$ & $S_{B 2}=\left(\begin{array}{ll}0.18 & 0.25\end{array}\right.$ & 0.22 & 0.21 & $0.14)$ \\
\hline$S_{c 4}=(0.10$ & 0.21 & $0.26 \quad 0.28$ & $0.15)$ & $S_{B 3}=\left(\begin{array}{ll}0.22 & 0.31\end{array}\right.$ & 0.18 & 0.17 & $0.12)$ \\
\hline$S_{c 5}=(0.22$ & 0.39 & $0.14 \quad 0.14$ & $0.11)$ & $S_{B 4}=\left(\begin{array}{ll}0.29 & 0.20\end{array}\right.$ & 0.23 & 0.19 & $0.09)$ \\
\hline$S_{c 6}=(0.13$ & 0.21 & $0.22 \quad 0.24$ & $0.20)$ & & & & \\
\hline$S_{c 7}=(0.13$ & 0.23 & $0.29 \quad 0.20$ & $0.16)$ & & & & \\
\hline$S_{c 8}=(0.33$ & 0.41 & 0.110 .10 & $0.05)$ & $S_{A}=\left(\begin{array}{ll}0.20 & 0.26\end{array}\right.$ & 0.23 & 0.19 & $0.12)$ \\
\hline$S_{c 9}=(0.09$ & 0.19 & $0.26 \quad 0.28$ & $0.19)$ & & & & \\
\hline$S_{c 10}=(0.29$ & 0.37 & $0.14 \quad 0.12$ & $0.08)$ & & & & \\
\hline$S_{c 11}=(0.19$ & 0.18 & $0.27 \quad 0.24$ & $0.12)$ & & & & \\
\hline$S_{c 12}=(0.59$ & 0.24 & $0.12 \quad 0.06$ & $0.00)$ & & & & \\
\hline
\end{tabular}

\section{Conclusions and countermeasures}

Analysis of evaluation results. According to the principle of maximum membership degree (0.26), the comprehensive evaluation level of human resources competitiveness of Company A is "better". Specifically: the overall evaluation level of human resources performance is "better"; the overall evaluation level of human resources practice is "better"; the evaluation level of human resources quality is "better"; the evaluation level of human resources environment is "very good".

\section{A company's human resources competitiveness improvement strategy}

(1) Transforming the concept of human resource management

The management of the company should change its concept, from traditional personnel management to modern human resource management, from human resource cost theory to human resource capital theory, and clarify the advantages of human resources in enterprise competition; human resources departments should change their role orientation. From strategic responders to strategy makers, a new business-oriented human resources work system was established.

(2) Strengthen human resource management practices

Optimize the salary structure, improve the incentive system, pay attention to the fairness of the salary system design; improve the incentive mechanism, combine long-term incentives with short-term incentives; reform the performance management system, consolidate and improve all aspects of performance management, and form a complete and unified performance cycle

(3) Improve the quality of human resources

Do a good job in recruiting, standardize the recruitment process, check the quality of human resources from the source; create a learning organization, establish a good team, organize a learning atmosphere, foster self-learning awareness and innovative spirit, and strive for sustainable competitive advantage.

\section{References}

[1] Shuming Zhao. The Relationship between Human Resources and Core Competitiveness[J]. Modern Economics Research, 2002(12): 16-19+73.(In Chinese)

[2] Ziemowit Czajkowski. Human Capital and Innovations As Determinants of Competitiveness[M].Springer International Publishing:2014-06-15.

[3] Andrea D. Ellinger,Valerie. The Generous Spirit of the Peer Review Process: Perspectives and Insights From the HRDQ Editorial Team on Providing High - Quality Reviews[J]. Human Resource Development Quarterly,2013,24(4).

[4] Xiuhua Liu. Construction Model of Enterprise Human Resource Competitiveness[J]. Journal of 
Shijiazhuang University of Economics, 2004(02): 134-137. .(In Chinese)

[5] Ming Li. Research on Enterprise Human Resource Competitiveness Evaluation Based on Interval Number Fuzzy Comprehensive Evaluation (IN-FCE)[J].Business Economics,2013,32(03):92-95. .(In Chinese)

[6] Dandan Xie. Research on the Construction of Human Resources Comprehensive Evaluation Index System Based on Core Competence in Civil Aviation Enterprises[J].China Market, 2017(32):155-156+164. .(In Chinese) 